\title{
Quick Switching Conditional RGS Plan-3 Indexed through Outgoing Quality Levels
}

\author{
V. Kaviyarasu \\ Department of Statistics, Bharathiar University, Coimbatore, Tamil Nadu, India \\ *Corresponding Author:kaviyarasu@buc.edu.in
}

Copyright $@ 2014$ Horizon Research Publishing All rights reserved.

\begin{abstract}
This paper tries to study the designing of new attribute sampling plan towards Quick Switching Conditional Repetitive Group Sampling System (QSCRGSS)-3 indexed through Average Outgoing Quality (AOQ), Average Outgoing Quality Limit (AOQL) and its Operating Ratio (OR). Tables are provided with numerical illustrations for newly developed plan for its various plan parameters.
\end{abstract}

Keyword Quick Switching System, Conditional Repetitive Group Sampling Plan, AOQ, AOQL and Operating Ratio

\section{Introduction}

Statistical Quality Control is widely used in industry to ensure customer satisfaction due to mass production of products and services. Acceptance sampling was widely used to test the quality of the product towards reduction of variability in process and product where variation is measured by statistical methods. An important field of statistical quality control is acceptance sampling which is either to accept or reject products of a lot under sample inspection when $100 \%$ inspection is not possible. The primary objective of sampling inspection is to reduce the cost of inspection while at the same time assuring the customer to an adequate level of quality for the items being inspected under identical conditions for both the producer and consumer.

This paper presents a new repetitive sampling plan for attributes which has considered by base and reference sampling plan. The Quick Switching System (QSS) as base plan and Conditional Repetitive Group Sampling Plan as reference plan to propose a new sampling plan called as Quick Switching Conditional Repetitive Group Sampling System (QSCRGSS)-3. Sampling plan is widely used in government sector and industry for controlling the quality of shipment of components, supplies and final products (e.g. life of electric bulbs, tensil strength and hardness of steel casting etc.,). Similar situations can be thought over the time where the quality of the product improves with decrease in the value of inspection cost.

\section{Quick Switching System}

Dodge (1967) proposed a new sampling inspection plan involving normal and tightened inspection which is usually referred as two-plan system. Romboski (1969) studies a Quick Switching System, switching to tightened inspection when the rejection comes under normal inspection. Due to instantaneous switching between normal and tightened plans, this system is referred as 'Quick Switching System (QSS)'. Romboski (1969) has further studied the merits and demerits of switching rules of QSS when it is compared with two-plan system $(m, d)$. The rule of QSS is retained at $m=1$ where as tightened rule is made when $\mathrm{d}>1$. Two natural choice for tightened rule for $\mathrm{d}=2, \mathrm{~d}=3$ etc., which are designed as QSS-2, QSS-3 and QSS-d. Schilling (1981) has mentioned the switching rules employed in the system are simple and the condition for application has evolved.

\section{Conditional Repetitive Group Sampling (CRGS) Plan}

The concept of Repetitive Group Sampling (RGS) plan was introduced by Sherman (1965) in which acceptance or rejection of a lot is based on the repeated sample results on the same lot. Soundararajan and Ramasamy (1986) has tabulated the values for selection of RGS plan indexed through (AQL, AOQL), $\left(\mathrm{p}_{0}, \mathrm{~h}_{0}\right)$ and $\left(\mathrm{p}_{*}, \mathrm{~h}_{*}\right)$. Gauri shankar and Mohapatra (1993) has developed a new Repetitive Group Sampling plan designated as Conditional Repetitive Group Sampling plan in which disposal of lot on the basis of repeated sample results is dependent on the outcome of the inspection of the immediate preceding $i$ lots. Further they derived the formulae for OC and ASN function.

Devraj Arumainayagam (1991) has studied QSS-1 with RGS plan as reference plan. Further Suresh and Kaviyarasu (2008) have studied QSS-1 and QSS-2 with Conditional RGS Plan as Reference plan indexed with Acceptable 
Quality Level (AQL), Limiting Quality Level (LQL), Indifference Quality Level (IQL) and AOQL. This paper provides a new procedure for selection of QSS-3 with Conditional RGS plan indexed through outgoing quality levels, which are tailor made for industrial shop floor applications.

\section{Designation}

QSCRGSS-3 $\left(n ; u_{1}, u_{2} ; v_{l}, v_{2}\right)$ refers to a Quick Switching System of type 3 where the normal CRGS plan has a sample size $n$ and acceptance number $u_{1}, u_{2}\left(u_{1}<u_{2}\right)$ and the tightened CRGS plan has a sample size $n$ and acceptance number $v_{1}, v_{2}\left(v_{1}<v_{2}, v_{l} \leq u_{1}\right.$ and $\left.v_{2} \leq u_{2}\right)$. The plan has six parameters namely $n, u_{1}, u_{2} ; v_{l}, v_{2}$ and $i$.

\section{Operating Procedure}

The Quick Switching Conditional Repetitive Group Sampling plan-3 is carried out through the following steps: Step 1: Draw a random sample of size $n$ and test each unit for its conformation for the specified requirements.

Step 2: Under normal inspection, inspect the plan under Conditional Repetitive Group Sampling plan with the parameters $n$,

$u_{1}$ and $u_{2}$. If lot is accepted, continue step 2 otherwise step 3.

Step3: Under tightened inspection, inspect the plan under Conditional Repetitive Group Sampling plan with the parameters $n$,

$v 1$ and $v 2$. If a lot is accepted, Continue step 3 for next 3 lots and goes to step 2, otherwise step 3.

Thus, the Quick Switching Conditional Repetitive Group Sampling Systems (QSCRGSS)-3 are characterized with six parameters namely, $\mathrm{n}, u_{1}, u_{2}, v_{l}, v_{2}$, and $i$. Here, it may be observed that when $u_{1}=u_{2}=v_{1}=v_{2}$, and $i=0$ the resulting plan is reduced to Repetitive Group Sampling plan due to Sherman (1965). Further, the Quick Switching Conditional Repetitive Group Sampling plan-3 is applicable to a stream of lots and not for isolated lots.

\section{Operating Characteristics Function}

Based on Sherman (1965), Romboski (1969), Arumainayagam (1991) and Jayalakshmi (2009) the expression for OC function of QSCRGSS-3 is given by,

$$
\mathrm{Pa}(\mathrm{p})=\frac{P_{N} P_{T}^{3}+P_{T}\left(1-P_{N}\right)\left(1+P_{T}\right)}{P_{T}^{3}+\left(1-P_{N}\right)\left(1+P_{T}\right)}
$$

Where,

$$
\mathrm{P}_{\mathrm{N}}=\frac{P_{r}\left(X \leq u_{1}\right)}{\left[1-p_{r}\left(X \leq u_{2}\right)+P_{r}\left(X \leq u_{1}\right)\right]}
$$

And

$$
\mathrm{P}_{\mathrm{T}}=\frac{P_{r}\left(X \leq v_{1}\right)}{\left[1-p_{r}\left(X \leq v_{2}\right)+P_{r}\left(X \leq v_{1}\right)\right]}
$$

\section{Glossary}

$\mathrm{N}=$ lot size

$\mathrm{n}=$ sample size

$\mathrm{p}=$ incoming quality of the submitted lot

$P_{a}(p)=$ Probability of Acceptance

$\mathrm{P}_{\mathrm{N}}=$ probability of acceptance under normal inspection

$\mathrm{P}_{\mathrm{T}}=$ probability of acceptance under tightened inspection $u_{1}$ and $u_{2}=$ acceptance numbers under normal inspection $v_{1}$ and $v_{2}=$ acceptance numbers under tightened inspection $\alpha=$ Consumer risk and $\beta=$ producer risk

$\mathrm{P}_{0.95}, \mathrm{P}_{0.50}=$ the lot or process quality for which the probability of acceptance is 0.95 and 0.50 etc., for given sampling plan

$\mathrm{i}=$ clearance interval

$\mathrm{P}_{\mathrm{L}}=$ Average Outgoing Quality Limit (AOQL) and

$\mathrm{P}_{\mathrm{m}}=$ Quality at which AOQL occurs.

\section{Designing QSCRGSS-3 for Different Parameters}

\subsection{Designing Systems for given $A Q L$ and $A O Q L$}

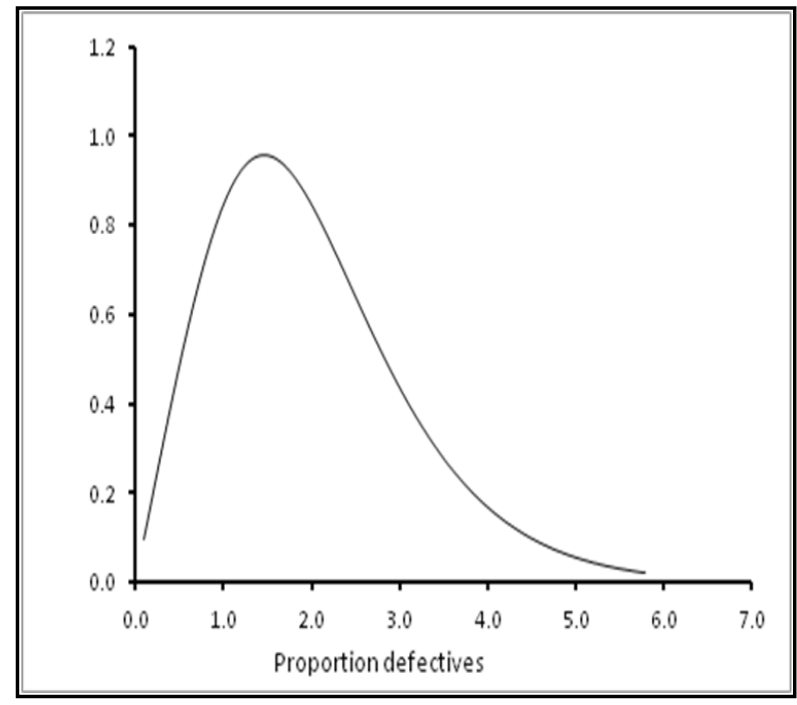

Figure 1. AOQ curve for QSCRGSS-3 Plan 
Table 2 can be used to design a QSCRGSS-3 indexed by AQL and AOQL. For example, given AQL $=5.1 \%(\alpha=0.05)$ and $\mathrm{AOQL}=7.04 \%$ one can compute $\mathrm{AOQL} / \mathrm{AQL}=7.04 / 5.1=1.38039$. From the table 1 the value of AOQL $/ \mathrm{AQL}$ closest to the desired value is 1.3704. This value corresponds to $u_{1}=1, u_{2}=4, v_{1}=1, v_{2}=3, \mathrm{i}=2$ and $\mathrm{np}_{1}=0.690$.

Table 1. AOQL values for QSCRGSS-3 when $\mathrm{i}=1$

\begin{tabular}{|c|c|c|c|c|c|c|c|c|}
\hline $\mathrm{u}_{1}$ & $\mathrm{u}_{2}$ & $\mathrm{v}_{1}$ & $\mathrm{v}_{2}$ & $\mathrm{np}_{\mathrm{m}}$ & $\mathrm{Pa}\left(\mathrm{np}_{\mathrm{m}}\right)$ & nAOQL & $\begin{array}{l}\mathrm{AOQL} / \mathrm{p}_{1} \\
\text { for } \alpha=0.05\end{array}$ & $\begin{array}{l}\mathrm{np}_{1} \text { for } \\
\alpha=0.05\end{array}$ \\
\hline 1 & 3 & 1 & 2 & 1.4701 & 0.6802 & 1.0000 & 1.2706 & 0.787 \\
\hline 1 & 4 & 1 & 2 & 1.4601 & 0.6944 & 1.0140 & 1.2291 & 0.825 \\
\hline 1 & 4 & 1 & 3 & 1.5501 & 0.6928 & 1.0740 & 1.2431 & 0.864 \\
\hline 1 & 5 & 1 & 2 & 1.4601 & 0.6976 & 1.0186 & 1.2272 & 0.830 \\
\hline 1 & 5 & 1 & 4 & 1.6001 & 0.6907 & 1.1052 & 1.2335 & 0.896 \\
\hline 2 & 3 & 1 & 2 & 1.5051 & 0.7892 & 1.1879 & 0.9999 & 1.188 \\
\hline 2 & 4 & 1 & 3 & 1.6051 & 0.8272 & 1.3278 & 0.9594 & 1.384 \\
\hline 2 & 5 & 1 & 3 & 1.6301 & 0.8382 & 1.3663 & 0.9745 & 1.402 \\
\hline 2 & 6 & 1 & 3 & 1.6401 & 0.8405 & 1.3786 & 0.9296 & 1.483 \\
\hline 2 & 6 & 1 & 5 & 1.6901 & 0.8347 & 1.4107 & 0.9275 & 1.521 \\
\hline 2 & 7 & 1 & 4 & 1.6801 & 0.8365 & 1.4053 & 1.0356 & 1.357 \\
\hline 2 & 7 & 1 & 6 & 1.7001 & 0.8331 & 1.4164 & 0.9455 & 1.498 \\
\hline 2 & 7 & 2 & 3 & 2.1601 & 0.7717 & 1.6669 & 1.0938 & 1.524 \\
\hline 2 & 7 & 2 & 5 & 2.3451 & 0.7603 & 1.7830 & 1.0999 & 1.621 \\
\hline 3 & 4 & 1 & 3 & 1.7601 & 0.8527 & 1.5008 & 0.8566 & 1.752 \\
\hline 3 & 4 & 2 & 3 & 2.2551 & 0.8070 & 1.8198 & 1.0065 & 1.808 \\
\hline 3 & 5 & 1 & 2 & 1.8022 & 0.8769 & 1.5803 & 0.8863 & 1.783 \\
\hline 3 & 5 & 2 & 3 & 2.2972 & 0.8431 & 1.9368 & 0.9402 & 2.060 \\
\hline 3 & 6 & 1 & 2 & 1.8561 & 0.8869 & 1.6462 & 0.7303 & 2.254 \\
\hline 3 & 6 & 1 & 5 & 1.9461 & 0.8878 & 1.7277 & 0.7621 & 2.267 \\
\hline 3 & 6 & 2 & 5 & 2.4661 & 0.8534 & 2.1046 & 0.8566 & 2.457 \\
\hline 3 & 7 & 2 & 4 & 2.4361 & 0.8597 & 2.0943 & 0.7361 & 2.845 \\
\hline 3 & 8 & 3 & 6 & 3.1061 & 0.8010 & 2.4880 & 1.1082 & 2.245 \\
\hline 4 & 6 & 2 & 3 & 2.5761 & 0.8825 & 2.2735 & 0.6987 & 3.254 \\
\hline 4 & 6 & 2 & 5 & 2.6861 & 0.8844 & 2.3757 & 0.6502 & 3.654 \\
\hline 4 & 7 & 3 & 6 & 3.2711 & 0.8645 & 2.8280 & 0.7545 & 3.748 \\
\hline 5 & 7 & 2 & 6 & 2.9951 & 0.9061 & 2.7140 & 0.6380 & 4.254 \\
\hline 5 & 7 & 3 & 6 & 3.4936 & 0.8877 & 3.1011 & 0.7116 & 4.358 \\
\hline 5 & 7 & 4 & 6 & 3.9461 & 0.8608 & 3.3966 & 0.7605 & 4.466 \\
\hline
\end{tabular}


Table 2. AOQL values for QSCRGSS-3 when $\mathrm{i}=2$

\begin{tabular}{|c|c|c|c|c|c|c|c|c|}
\hline $\mathrm{u}_{1}$ & $\mathrm{u}_{2}$ & $\mathrm{v}_{1}$ & $\mathrm{v}_{2}$ & $\mathrm{np}_{\mathrm{m}}$ & $\mathrm{Pa}\left(\mathrm{np}_{\mathrm{m}}\right)$ & nAOQL & $\begin{array}{c}\mathrm{AOQL} / \mathrm{p}_{1} \text { for } \\
\alpha=0.05\end{array}$ & $\begin{array}{l}\mathrm{np}_{1} \text { for } \\
\alpha=0.05\end{array}$ \\
\hline 1 & 3 & 1 & 2 & 1.4501 & 0.6329 & 0.9177 & 1.3596 & 0.675 \\
\hline 1 & 4 & 1 & 2 & 1.4351 & 0.6426 & 0.9222 & 1.3269 & 0.685 \\
\hline 1 & 4 & 1 & 3 & 1.4602 & 0.6522 & 0.9524 & 1.3704 & 0.690 \\
\hline 1 & 5 & 1 & 2 & 1.4401 & 0.6413 & 0.9235 & 1.3288 & 0.695 \\
\hline 1 & 5 & 1 & 4 & 1.4852 & 0.6499 & 0.9652 & 1.3808 & 0.699 \\
\hline 2 & 3 & 1 & 2 & 1.4252 & 0.7817 & 1.1141 & 0.9947 & 1.120 \\
\hline 2 & 4 & 1 & 3 & 1.4602 & 0.8182 & 1.1947 & 0.9497 & 1.258 \\
\hline 2 & 5 & 1 & 3 & 1.4752 & 0.8233 & 1.2145 & 0.9511 & 1.277 \\
\hline 2 & 6 & 1 & 3 & 1.4803 & 0.8240 & 1.2197 & 0.9390 & 1.299 \\
\hline 2 & 6 & 1 & 5 & 1.5001 & 0.8213 & 1.2320 & 0.9298 & 1.325 \\
\hline 2 & 7 & 1 & 4 & 1.4952 & 0.8228 & 1.2303 & 0.9486 & 1.297 \\
\hline 2 & 7 & 1 & 6 & 1.5005 & 0.8224 & 1.2339 & 0.9499 & 1.299 \\
\hline 2 & 7 & 2 & 3 & 2.0786 & 0.7359 & 1.5296 & 0.6813 & 2.245 \\
\hline 2 & 7 & 2 & 5 & 2.1736 & 0.7331 & 1.5935 & 0.6934 & 2.298 \\
\hline 3 & 4 & 1 & 3 & 1.6485 & 0.8517 & 1.4040 & 0.6420 & 2.187 \\
\hline 3 & 4 & 2 & 3 & 2.1612 & 0.8046 & 1.7389 & 0.9988 & 1.741 \\
\hline 3 & 5 & 1 & 2 & 1.6973 & 0.8714 & 1.4790 & 0.8888 & 1.664 \\
\hline 3 & 5 & 2 & 3 & 2.1756 & 0.8351 & 1.8169 & 0.9488 & 1.915 \\
\hline 3 & 6 & 1 & 2 & 1.7273 & 0.8789 & 1.5182 & 0.7850 & 1.934 \\
\hline 3 & 6 & 1 & 5 & 1.7623 & 0.8797 & 1.5503 & 0.7922 & 1.957 \\
\hline 3 & 6 & 2 & 5 & 2.2523 & 0.8458 & 1.9051 & 0.8965 & 2.125 \\
\hline 3 & 7 & 2 & 4 & 2.2423 & 0.8476 & 1.9006 & 0.8074 & 2.354 \\
\hline 3 & 8 & 3 & 6 & 2.8923 & 0.7814 & 2.2601 & 0.8535 & 2.648 \\
\hline 4 & 6 & 2 & 3 & 2.4512 & 0.8812 & 2.1601 & 0.5859 & 3.687 \\
\hline 4 & 6 & 2 & 5 & 2.4692 & 0.8935 & 2.2061 & 0.5838 & 3.779 \\
\hline 4 & 7 & 3 & 6 & 3.0306 & 0.8597 & 2.6054 & 0.6584 & 3.957 \\
\hline 5 & 7 & 2 & 6 & 2.8056 & 0.9070 & 2.5447 & 0.6322 & 4.025 \\
\hline 5 & 7 & 3 & 6 & 3.2823 & 0.8889 & 2.9175 & 0.6564 & 4.445 \\
\hline 5 & 7 & 4 & 6 & 3.7523 & 0.8595 & 3.2252 & 0.6778 & 4.758 \\
\hline
\end{tabular}

\subsection{Determining the value of $A O Q L$ of a given system}

Table 1 can be used to obtain the values of AOQL and $\mathrm{p}_{\mathrm{m}}$ for a given system. For example, QSCRGSS-3(63; 3, 8; 3, 6) when $i=1$, from table 1 , corresponding to these entry plan parameters one can get $\mathrm{nAOQL}=2.4880$ and $\mathrm{np}_{\mathrm{m}}=3.1061$. So $\mathrm{AOQL}=\mathrm{nAOQL} / \mathrm{n}=2.4880 / 63=0.03949$ and $\mathrm{p}_{\mathrm{m}}=\mathrm{np}_{\mathrm{m}} / \mathrm{n}=3.1061 / 63=0.04930$.

\subsection{Conversion from one set of parameters to the other}

Table 1 can be used to convert the given set of parameters to another familiar equivalent set. For example, for given AQL $=0.05, \alpha=0.05, \mathrm{LQL}=0.09$ and $\beta=0.10$, from the Table one can fix the QSCRGSS-3 plan as $\mathrm{n}=55, u_{1}=3, u_{2}=4, v_{l}=2$, $v_{2}=3$ when $i=1$. Corresponding to these entry parameters, one can find the following values from tables.

$\mathrm{np}_{1}=1.808 \quad \mathrm{np}_{\mathrm{m}}=2.2551 \quad \mathrm{nAOQL}=1.8198$

$\mathrm{np}_{0}=2.2954 \quad \mathrm{~h}_{0}=1.8461$

From these values, one can find the equivalent parameters of QSCRGSS-3 as follows: 
$\mathrm{AQL}(\alpha=0.05)=0.05, \mathrm{AOQL}=\mathrm{nAOQL} / \mathrm{n}=1.8198 / 55=0.03308$

$\mathrm{IQL}=\mathrm{np}_{0} / \mathrm{n}=2.2954 / 55=0.04173$

Thus, for given (AQL, 1- $\alpha$ ) and (LQL, $\beta)$, other equivalent parameters were (AQL, AOQL) and $\left(\mathrm{p}_{0}, \mathrm{~h}_{0}\right)$ are $(0.05,0.03308)$ and $(0.04173,1.8461)$.

\subsection{Designing Systems given $p_{1}, \alpha, p_{2}$ and $\beta$}

Table 3 can be used to design Quick Switching Conditional Repetitive Group Sampling System (QSCRGSS)-3, when two points on the OC curve $\left(p_{1}, 1-\alpha\right)$ and $\left(p_{2}, \beta\right)$ are given. To design a QSCRGSS-3 the operating ratio $(O R)=p_{2} / p_{1}$. From table 3 , one can determine the value of OR which is nearer to the desired ratio. Corresponding to the selected OR values of $u_{1}, u_{2}, v_{l}$, $v_{2}$ and $\mathrm{np}_{1}$ when $i=1$. The sample size is determined by dividing $\mathrm{np}_{1}$ by $\mathrm{p}_{1}$.

For example, let $\mathrm{p}_{1}=0.05, \alpha=0.05, \mathrm{p}_{2}=0.395$ and $\beta=0.10$, calculate the Operating Ratio $(\mathrm{OR})=\mathrm{p}_{2} / \mathrm{p}_{1}=0.395 / 0.05=$ 7.9. From the table 3 the value of OR for $\alpha=0.05$ and $\beta=0.10$ which is the nearest to the desired ratio is 8.0731 . Corresponding to this selected OR values are $u_{1}=1, u_{2}=2, v_{1}=0, v_{2}=1$ when $i=1$ and $\mathrm{np}_{1}=0.372$. The sample size is obtained as $n=\mathrm{np}_{1} / \mathrm{p}_{1}=0.372 / 0.05=7.44 \sim 7$. The desired system is $\operatorname{QSCRGSS}-3(7 ; 1,2)$ for normal and $(7 ; 0,1)$ for tightened case when $i=1$.

Table 3. Operating Ratio values for QSCRGSS-3 $\left(n, u_{1}, u_{2}, v_{1}, v_{2}\right)$ when $i=1$

\begin{tabular}{|c|c|c|c|c|c|c|c|c|c|c|c|}
\hline & & & & \multicolumn{4}{|c|}{$\mathrm{p}_{2} / \mathrm{p}_{1}$ for $\alpha=0.01$} & \multicolumn{4}{|c|}{$\mathrm{p}_{2} / \mathrm{p}_{1}$ for $\alpha=0.05$} \\
\hline $\mathrm{u}_{1}$ & $\mathrm{u}_{2}$ & $v_{1}$ & $\mathrm{v}_{2}$ & $\begin{array}{l}\alpha=0.01 \\
\beta=0.10\end{array}$ & $\begin{array}{l}\alpha=0.01 \\
\beta=0.05\end{array}$ & $\begin{array}{l}\alpha=0.01 \\
\beta=0.01\end{array}$ & $\begin{array}{l}\mathrm{np}_{1} \text { for } \\
\alpha=0.01\end{array}$ & $\begin{array}{l}\alpha=0.05 \\
\beta=0.10\end{array}$ & $\begin{array}{l}\alpha=0.05 \\
\beta=0.05\end{array}$ & $\begin{array}{l}\alpha=0.05 \\
\beta=0.01\end{array}$ & $\begin{array}{r}\mathrm{np}_{1} \text { for } \\
\alpha=0.05 \\
\end{array}$ \\
\hline 0 & 2 & 0 & 1 & 47.979 & 20.381 & 14.349 & 0.096 & 31.260 & 13.279 & 9.349 & 0.226 \\
\hline 0 & 3 & 0 & 2 & 47.927 & 20.358 & 13.900 & 0.096 & 31.396 & 13.336 & 9.106 & 0.226 \\
\hline 0 & 3 & 0 & 1 & 47.979 & 20.381 & 14.716 & 0.096 & 31.250 & 13.274 & 9.585 & 0.226 \\
\hline 0 & 4 & 0 & 1 & 45.196 & 20.308 & 14.098 & 0.102 & 29.431 & 13.225 & 9.180 & 0.227 \\
\hline 1 & 2 & 0 & 1 & 12.374 & 7.710 & 6.465 & 0.372 & 8.073 & 5.030 & 4.218 & 0.597 \\
\hline 1 & 3 & 1 & 2 & 13.494 & 8.436 & 6.726 & 0.492 & 9.644 & 6.029 & 4.807 & 0.787 \\
\hline 1 & 3 & 0 & 1 & 9.804 & 6.737 & 5.840 & 0.470 & 6.379 & 4.383 & 3.800 & 0.684 \\
\hline 1 & 4 & 1 & 2 & 13.303 & 8.046 & 6.445 & 0.499 & 9.509 & 5.752 & 4.607 & 0.825 \\
\hline 1 & 4 & 0 & 2 & 9.123 & 6.320 & 5.491 & 0.505 & 5.966 & 4.133 & 3.591 & 0.729 \\
\hline 1 & 5 & 1 & 2 & 12.889 & 7.998 & 6.383 & 0.515 & 9.223 & 5.723 & 4.567 & 0.830 \\
\hline 1 & 5 & 0 & 2 & 9.171 & 6.290 & 5.468 & 0.502 & 6.002 & 4.116 & 3.578 & 0.732 \\
\hline 1 & 5 & 0 & 1 & 9.299 & 6.501 & 5.697 & 0.495 & 6.061 & 4.237 & 3.713 & 0.708 \\
\hline 2 & 3 & 1 & 2 & 8.617 & 5.585 & 4.706 & 0.770 & 6.165 & 3.996 & 3.367 & 1.188 \\
\hline 2 & 4 & 1 & 2 & 6.764 & 4.850 & 4.259 & 0.981 & 4.844 & 3.474 & 3.050 & 1.368 \\
\hline 2 & 6 & 1 & 3 & 6.198 & 4.476 & 3.956 & 1.071 & 4.440 & 3.206 & 2.834 & 1.483 \\
\hline 2 & 6 & 1 & 2 & 6.233 & 4.584 & 4.065 & 1.065 & 4.459 & 3.280 & 2.908 & 1.448 \\
\hline 2 & 6 & 0 & 1 & 5.357 & 4.429 & 4.076 & 0.859 & 3.496 & 2.890 & 2.660 & 1.039 \\
\hline 2 & 7 & 1 & 2 & 6.215 & 4.568 & 4.060 & 1.068 & 4.445 & 3.267 & 2.903 & 1.453 \\
\hline 2 & 7 & 0 & 3 & 5.152 & 4.233 & 3.910 & 0.894 & 3.381 & 2.778 & 2.566 & 1.088 \\
\hline 2 & 7 & 0 & 1 & 5.375 & 4.429 & 4.429 & 0.857 & 3.506 & 2.889 & 2.889 & 1.040 \\
\hline 3 & 4 & 2 & 3 & 6.817 & 4.649 & 3.955 & 1.233 & 5.109 & 3.485 & 2.965 & 1.808 \\
\hline 3 & 4 & 0 & 1 & 5.047 & 4.147 & 3.820 & 0.912 & 3.295 & 2.707 & 2.494 & 1.110 \\
\hline 3 & 5 & 1 & 2 & 4.598 & 3.721 & 3.432 & 1.443 & 3.292 & 2.664 & 2.457 & 1.783 \\
\hline 3 & 5 & 2 & 3 & 5.516 & 4.081 & 3.608 & 1.524 & 4.135 & 3.059 & 2.704 & 2.060 \\
\hline 3 & 8 & 0 & 4 & 3.824 & 3.315 & 3.114 & 1.205 & 2.524 & 2.188 & 2.055 & 1.390 \\
\hline 3 & 12 & 0 & 1 & 3.975 & 3.427 & 3.210 & 1.158 & 2.604 & 2.245 & 2.103 & 1.343 \\
\hline
\end{tabular}


Table 4. Operating Ratio values for QSCRGSS-3 ( $\left.n, u_{1}, u_{2}, v_{1}, v_{2}\right)$ when $i=2$

\begin{tabular}{|c|c|c|c|c|c|c|c|c|c|c|c|}
\hline \multirow[b]{2}{*}{$\mathrm{u}_{1}$} & \multirow[b]{2}{*}{$\mathrm{u}_{2}$} & \multirow[b]{2}{*}{$\mathrm{v}_{1}$} & \multirow[b]{2}{*}{$\mathrm{v}_{2}$} & \multicolumn{4}{|c|}{$\mathrm{p}_{2} / \mathrm{p}_{1}$ for $\alpha=0.01$} & \multicolumn{4}{|c|}{$\mathrm{p}_{2} / \mathrm{p}_{1}$ for $\alpha=0.05$} \\
\hline & & & & $\begin{array}{l}\alpha=0.01 \\
\beta=0.10\end{array}$ & $\begin{array}{l}\alpha=0.01 \\
\beta=0.05\end{array}$ & $\begin{array}{l}\alpha=0.01 \\
\beta=0.01\end{array}$ & $\begin{array}{l}\mathrm{np}_{1} \text { for } \\
\alpha=0.01\end{array}$ & $\begin{array}{l}\alpha=0.05 \\
\beta=0.10\end{array}$ & $\begin{array}{l}\alpha=0.05 \\
\beta=0.05\end{array}$ & $\begin{array}{l}\alpha=0.05 \\
\beta=0.01\end{array}$ & $\begin{array}{l}\mathrm{np}_{1} \text { for } \\
\alpha=0.05\end{array}$ \\
\hline 0 & 2 & 0 & 1 & 67.721 & 44.044 & 33.824 & 0.068 & 28.252 & 18.374 & 14.110 & 0.163 \\
\hline 0 & 3 & 0 & 1 & 65.786 & 42.786 & 32.900 & 0.070 & 27.411 & 17.827 & 13.708 & 0.168 \\
\hline 0 & 3 & 0 & 2 & 64.859 & 42.183 & 32.465 & 0.071 & 27.411 & 17.827 & 13.720 & 0.168 \\
\hline 0 & 4 & 0 & 1 & 63.958 & 41.583 & 32.000 & 0.072 & 27.411 & 17.821 & 13.714 & 0.168 \\
\hline 1 & 2 & 0 & 1 & 13.544 & 13.544 & 8.800 & 0.340 & 8.607 & 8.607 & 5.593 & 0.535 \\
\hline 1 & 3 & 0 & 1 & 11.370 & 7.388 & 5.691 & 0.405 & 7.805 & 5.071 & 3.907 & 0.590 \\
\hline 1 & 3 & 1 & 2 & 15.988 & 11.427 & 9.369 & 0.415 & 9.830 & 7.025 & 5.760 & 0.675 \\
\hline 1 & 4 & 0 & 2 & 16.590 & 7.217 & 5.566 & 0.415 & 11.287 & 4.910 & 3.787 & 0.610 \\
\hline 1 & 4 & 1 & 2 & 15.414 & 11.158 & 9.153 & 0.425 & 9.426 & 6.823 & 5.597 & 0.695 \\
\hline 1 & 5 & 0 & 1 & 16.537 & 7.300 & 5.629 & 0.410 & 11.262 & 4.972 & 3.834 & 0.602 \\
\hline 1 & 5 & 0 & 2 & 11.096 & 7.217 & 5.549 & 0.415 & 7.549 & 4.910 & 3.775 & 0.610 \\
\hline 1 & 5 & 1 & 2 & 15.505 & 11.075 & 9.089 & 0.428 & 9.548 & 6.820 & 5.597 & 0.695 \\
\hline 2 & 3 & 1 & 2 & 8.966 & 6.409 & 5.262 & 0.740 & 5.924 & 4.235 & 3.477 & 1.120 \\
\hline 2 & 4 & 1 & 2 & 7.497 & 5.356 & 4.398 & 0.885 & 5.346 & 3.820 & 3.136 & 1.241 \\
\hline 2 & 6 & 0 & 2 & 6.004 & 3.905 & 3.030 & 0.767 & 4.899 & 3.186 & 2.472 & 0.940 \\
\hline 2 & 6 & 1 & 2 & 7.134 & 5.099 & 4.183 & 0.930 & 5.180 & 3.702 & 3.037 & 1.281 \\
\hline 2 & 6 & 1 & 3 & 7.096 & 5.075 & 4.166 & 0.935 & 5.108 & 3.653 & 2.998 & 1.299 \\
\hline 2 & 7 & 0 & 1 & 6.091 & 3.962 & 3.069 & 0.756 & 4.952 & 3.220 & 2.495 & 0.930 \\
\hline 2 & 7 & 0 & 3 & 5.964 & 3.880 & 3.014 & 0.772 & 4.872 & 3.169 & 2.462 & 0.945 \\
\hline 2 & 7 & 1 & 2 & 7.129 & 5.097 & 4.183 & 0.930 & 5.164 & 3.692 & 3.030 & 1.284 \\
\hline 3 & 4 & 0 & 1 & 5.311 & 3.460 & 2.710 & 0.867 & 4.353 & 2.836 & 2.221 & 1.058 \\
\hline 3 & 4 & 2 & 3 & 6.976 & 5.224 & 4.419 & 1.205 & 4.828 & 3.616 & 3.059 & 1.741 \\
\hline 3 & 5 & 1 & 2 & 4.915 & 3.513 & 2.889 & 1.350 & 3.987 & 2.850 & 2.344 & 1.664 \\
\hline 3 & 5 & 2 & 3 & 5.897 & 4.418 & 3.736 & 1.425 & 4.388 & 3.287 & 2.780 & 1.915 \\
\hline 3 & 8 & 0 & 4 & 4.301 & 2.806 & 2.224 & 1.070 & 3.699 & 2.413 & 1.913 & 1.244 \\
\hline 3 & 12 & 0 & 1 & 4.342 & 2.830 & 2.244 & 1.060 & 3.727 & 2.429 & 1.926 & 1.235 \\
\hline
\end{tabular}

\subsection{Operating Ratio}

\section{Designing Systems for given Operating Ratio}

Table 3 and 4 can be used to design QSRGSS-3, when two points on the OC curve $\left(p_{1}, 1-\alpha\right)$ and $\left(p_{2}, \beta\right)$ are given. To design a QSRGSS-3 calculate the Operating Ratio (OR) $=\mathrm{p}_{2} / \mathrm{p}_{1}$. From table 3 and 4 , one can determine the value of OR which is nearer to the desired ratio, corresponding to the selected OR values of $u_{1}, u_{2}, v_{1}, v_{2}, i$ and $\mathrm{np}_{1}$. The sample size is determined by dividing $\mathrm{np}_{1}$ by $\mathrm{p}_{1}$.

For example, let $\mathrm{p}_{1}=0.02, \alpha=0.05, \mathrm{p}_{2}=0.086$ and $\beta=$ 0.10 , calculate the Operating Ratio $(\mathrm{OR})=\mathrm{p}_{2} / \mathrm{p}_{1}=0.086 /$
$0.02=4.3$. From table 2.5.1, the value of OR for $\alpha=0.05$ and $\beta=0.05$ which is the nearest to the desired ratio is 4.3424. Corresponding to this selected OR the parameters are $u_{1}=1, u_{2}=3, v_{1}=1, v_{2}=2$ and $\mathrm{np}_{1}=1.1191$. The sample size is obtained as $n=\mathrm{np}_{1} / \mathrm{p}_{1}=1.1191 / 0.02=$ $55.955 \cong 56$. The desired system is QSRGSS-3 $(56 ; 1,3 ; 1$, 2).

\subsection{Construction of Tables}

The expression for probability of acceptance of Quick Switching Conditional Repetitive Group Sampling System (QSCRGSS)-3, under the assumption of Poisson model, the 
composite OC function is given by equation (1) with

$$
\begin{aligned}
& \mathbf{P}_{\mathrm{N}}=\frac{\sum_{x=o}^{u_{1}} e^{-n p}(n p)^{x} / x !}{1+\left[\sum_{x=0}^{u_{1}} e^{-n p}(n p)^{x} / x !-\sum_{x=0}^{u_{2}} e^{-n p}(n p)^{x} / x !\left[\sum_{x=0}^{u_{1}} e^{-n p}(n p)^{x} / x !\right]^{i}\right.} \\
& \mathbf{P}_{\mathrm{T}}=\frac{\sum_{x=o}^{v_{1}} e^{-n p}(n p)^{x} / x !}{1+\left[\sum_{x=0}^{v_{1}} e^{-n p}(n p)^{x} / x !-\sum_{x=0}^{v_{2}} e^{-n p}(n p)^{x} / x !\right]\left[\sum_{x=0}^{v_{1}} e^{-n p}(n p)^{x} / x !\right]^{i}}
\end{aligned}
$$

For various assumed values of $u_{1}, u_{2}, v_{1}, v_{2}, i$ and $\mathrm{P}_{\mathrm{a}}(\mathrm{p})$ the equation (1) is solved with the equation (4) and (5) one can get the $n p$ using iteration techniques from $\mathrm{c}++$ computer program and values are obtained. Utilizing the $n p$ values tabulated for different values of $u_{1}, u_{2}, v_{1}, v_{2}$ and $i$. From table 1 and 2 the various outgoing quality levels and Operating Ratio values are calculated for different $\alpha$ and $\beta$ values are given in table 3 and 4. Assuming $n A O Q=n p * P a(p)$, value of np which maximizes nAOQ was obtained by the method of successive approximation and these values $\left(n p_{m}\right)$ together with $\mathrm{nAOQL}\left(=\mathrm{np}_{\mathrm{m}} * \mathrm{~Pa}\left(\mathrm{p}_{\mathrm{m}}\right)\right)$ appear in table 1 to 2 .

\section{Conclusion}

Acceptance sampling is a technique which gives a better solution to the problems faced by the industry. Acceptance sampling itself does not improve quality, but whenever the lot is rejected it indicates the instability of the production process. Acceptance sampling is a cost efficient one and only an admissible method which is used for destructive and costly tests which provides quick results. Sampling plans are necessary to provide the disposal of defective products made, while efforts are activated to control the process. In that Quick Switching System and Conditional RGS Plan have wide potential applicability in industries to ensure a high standard of quality attainment and increased customer satisfaction. Here, an attempt is made towards the concept of Quick Switching Conditional Repetitive Group Sampling System (QSCRGSS)-3 in which disposal of a lot is on the basis of normal and tightened plans. Poisson unity values have been tabulated for a wide range of plan parameters. The present development would be valuable addition in the literature and a useful device to the quality practitioners. The concept of this article may be of assistance to quality control engineers and plan designers in the development of further plans.

\section{REFERENCES}

\section{AMERICAN}

\section{NATIONAL}

STANDARDS, Institute/American Society for Quality Control (ANSI/ASQC) STANDARD A2 (1987): "Terms, symbols and Definition for Acceptance Sampling", American Society for Quality Control, Milwaukee, Wisconsin. USA.

[2] ARUMAINAYAGAM, S. D. (1991): "Contribution to the Study of Quick Switching System and its Application", Ph.D., Thesis, Department of Statistics, Bharathiar University Coimbatore, Tamilnadu, India.

[3] DODGE, H. F. (1967): Notes on the Evolution of Acceptance Sampling Plans, Journal of Quality Technology. Vol.1, No.2, pp. 77-88.

[4] GAURI SANKAR and MOHAPATRA, B. N. (1993): GERT Analysis of Conditional Repetitive Group Sampling Plan, International Journal of Quality \& Reliability Management, Vol.10, No.2, pp 50-62.

[5] GAURI SANKAR and JOSEPH, S. (1994): GERT Analysis of Multiple Repetitive Group Sampling Plans, IAPQR Transactions, Vol.19, No.2, pp. 7-19.

[6] JAYALAKSHMI, S. (2009): Contribution to the Selection of Quick Switching System and related sampling plans, Ph.D Thesis, Department of Statistics, Bharathiar University, Coimbatore, Tamil Nadu, India.

[7] KAVIYARASU, V. and SURESH, K. K. (2011): Certain Results and Tables Relating to QSS-1 with Multiple RGS Plan, Journal of Mathematical Research, Canadian Center of Science and Education, Canada Vol.3, No.4, pp.158-167, Nov 2011.

[8] ROMBOSKI, L. D. (1969): “An Investigation of Quick Switching Acceptance Sampling Systems", Ph.D Thesis, Rutgers- The State University, New Brunswick, New Jersey.

[9] SCHILLING, E. G. (1981): A modified general procedure for sampling inspection, Frontiers in Statistical Quality Control, Edited Lenz, H.J., Wetherill, G.B., Wilrich, P.Th. Wilrich.

[10] SHERMAN, R. E. (1965): "Design and Evaluation of Repetitive Group Sampling Plans", Technometrics, Vol.7, No.1, pp.11-21.

[11] SOUNDARARAJAN, V. and RAMASAMY, M. M. (1986): Procedures and Tables for Construction and Selection of Repetitive Group Sampling (RGS) Plan, the QR Journal, Vol.13, No.3, pp.19-21.

[12] SURESH, K. K. and KAVIYARASU, V. (2008): Certain Results and Tables Relating to QSS-1 with Conditional RGS Plan, IAPQR Transactions, India, Vol.33, No.1, pp. 61-70. 